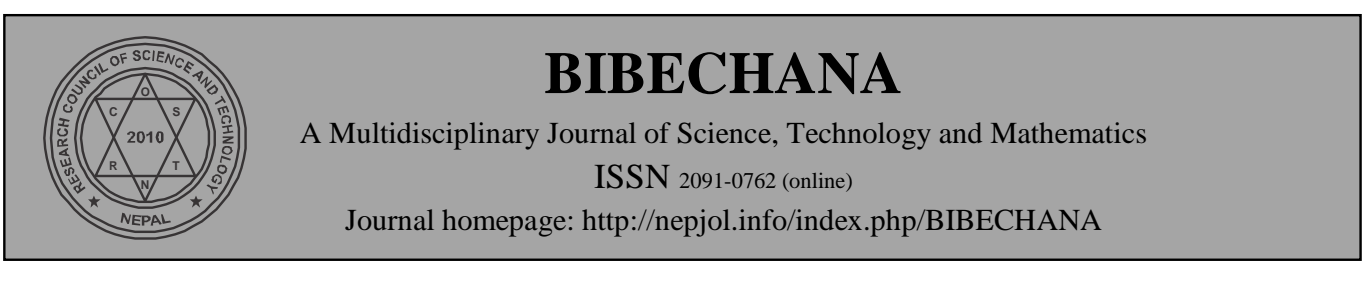

\title{
Micellization behaviour of sodium dodecyl sulphate in presence and absence of sodium sulphate and zinc sulphate in distilled water by surface tension measurement
}

\author{
Kuber Limbu, Sujit Kumar Shah, Ajaya Bhattarai* \\ Department of Chemistry, M.M.A.M. C. (Tribhuvan University), Biratnagar, Nepal \\ "Corresponding Author: E-mail: bkajaya@ yahoo.com \\ Accepted for publication: February 15, 2014
}

\begin{abstract}
The accurate measurements of surface tension of sodium dodecyl sulphate (SDS) in distilled water and in presence of $0.01 \mathrm{M} \mathrm{Na} \mathrm{SO}_{4}$ and $0.01 \mathrm{M} \mathrm{ZnSO}_{4}$ at room temperature were reported by drop weight method using a stalagmometer. The critical micelle concentration $(\mathrm{cmc})$ of sodium dodecyl sulphate (SDS) in distilled water was obtained higher than in presence of $\mathrm{Na}_{2} \mathrm{SO}_{4}$ and $\mathrm{ZnSO}_{4}$. The decrease of cmc of sodium dodecyl sulphate in the presence of salts has been discussed.
\end{abstract}

(C) 2014 RCOST: All rights reserved.

Keywords: Stalagmometer; Sodium dodecyl sulphate; Surface tension; Critical micelle Concentration; Sodium sulphate; Zinc sulphate.

\section{Introduction}

Due to the different environment of molecules located at an interface compared to those from either bulk phase, an interface is associated with a surface free energy. At the air-water surface for example, water molecules are subjected to unequal short-range attraction forces and, thus, undergo a net inward pull to the bulk phase. Minimization of the contact area with the gas phase is therefore a spontaneous process, explaining why drops and bubbles are round. The surface free energy per unit area, defined as the surface tension $(\gamma)$. Another, but less intuitive, definition of surface tension is given as the force acting normal to the liquid-gas interface per unit length of the resulting thin film on the surface.

Surfactants reduce the amount of work necessary to create unit surface area i.e. surface tension of a solution is lowered when surfactants are present [1]. The limiting value of surfactant concentration that produces a surface tension decrease is the critical micelle concentration [2]. Furthermore, the steeper decrease in surface tension is evident only at high surfactant concentrations. Since, due to the surface activity of the surfactant, surface tension measurement is the major method for the determination of cmc. In tensiometric determination of the $\mathrm{cmc}$ of pure surfactants, the surface tensions $(\gamma)$ are plotted as a function of logarithm of the surfactant concentration. The following equation is used to calculate the surface tension of required solution. 
K. Limbu et al. / BIBECHANA 11(1) (2014) 79-85: (Online Publication: March, 2014) p.80

$$
\begin{aligned}
& \gamma_{\text {soln }}=\left(\frac{n_{\text {solv }}}{n_{\text {soln }}}\right)\left(\frac{d_{\text {soln }}}{d_{\text {solv }}}\right) \gamma_{\text {solv }} \\
& \text { where, } \\
& \gamma_{\text {soln }}=\text { surface tension of solution } \\
& \gamma_{\text {solv }}=\text { surface tension of solvent } \\
& n_{\text {soln }}=\text { number of drops of solution } \\
& n_{\text {solv }}=\text { number of drops of solvent } \\
& d_{\text {soln }}=\text { density of solution } \\
& d_{\text {solv }}=\text { density of solvent }
\end{aligned}
$$

Sodium dodecyl sulphate (SDS) is an anionic surfactant. One end of the molecule is charged and therefore has an affinity for water, and the other end is non polar and soluble in fat/oil. SDS has a negatively charged sulfonate group as its "hydrophilic" end and a saturated 12-carbon for its "lipophilic" end. Sodium dodecyl sulphate has significant application as very effective surfactant in a number of industrial products and in recent studies it is considered as a novel microbicide against different viruses $[3,4]$.

In this paper, we report a study of the micellization behaviour of sodium dodecyl sulphate (SDS) at room temperature in absence and in presence of $\mathrm{Na}_{2} \mathrm{SO}_{4}$ and $\mathrm{ZnSO}_{4}$ by surface tension method in aqueous media.

\section{Experimental}

Sodium dodecyl sulphate was purchased from Loba Chemical, India. $\mathrm{ZnSO}_{4}$ and $\mathrm{Na}_{2} \mathrm{SO}_{4}$ were purchased from Ranbaxy Chemical, India. The water used in the experiments was doubly distilled. The solutions prepared at room temperature.

For the preparation of experimental solution of SDS in distilled water, $2.8838 \mathrm{~g}$ of pure SDS was weighed accurately with digital balance and was dissolved in $100 \mathrm{ml}$ of distilled water to get $0.1 \mathrm{M}$ SDS solution. $0.1 \mathrm{M}$ SDS solution was used as stock solution $\left(\mathrm{s}_{\mathrm{o}}\right)$ for the preparation of different eight solutions of different concentrations viz. $0.08 \mathrm{M}\left(\mathrm{s}_{1}\right), 0.06 \mathrm{M}\left(\mathrm{s}_{2}\right), 0.04 \mathrm{M}\left(\mathrm{s}_{3}\right), 0.024 \mathrm{M}\left(\mathrm{s}_{4}\right), 0.018 \mathrm{M}\left(\mathrm{s}_{5}\right), 0.012 \mathrm{M}\left(\mathrm{s}_{6}\right)$, $0.00725 \mathrm{M}\left(\mathrm{s}_{7}\right), 0.0054 \mathrm{M}\left(\mathrm{s}_{8}\right)$. These different solutions were prepared by diluting the appropriate volume of stock solution $\left(\mathrm{s}_{\mathrm{o}}\right)$ with distilled water in $50 \mathrm{ml}$ volumetric flasks.

Similarly, as described above the same weight of pure SDS was weighed and was dissolved in $100 \mathrm{ml}$ of $0.01 \mathrm{M} \mathrm{Na}_{2} \mathrm{SO}_{4}$ and $0.01 \mathrm{M} \mathrm{ZnSO}_{4}$ separately to get $0.1 \mathrm{M}$ SDS in non-aqueous environments. Here also eight different solutions were prepared for each of solvents with stock solutions: $A_{0}, A_{1}, A_{2}, A_{3}, A_{4}, A_{5}, A_{6}$, $A_{7}, A_{8}$ and $D_{0}, D_{1}, D_{2}, D_{3}, D_{4}, D_{5}, D_{6}, D_{7}, D_{8}$ respectively with equivalent concentrations.

The weights of the different solutions of SDS with different strengths were measured by the pyknometer (specific gravity bottle). For this purpose, the cleaned pyknometer was taken and was first filled with airfree distilled water in it, then the stopper was inserted into its mouth so that the small amount of water flowed out the capillary then the outer surface of it was wiped out with a tissue paper ensuring that outer surface was completely dried. Finally, the bottle was weighed and then emptied and dried. Then, the same process was repeated for every type of solutions under investigations. After collecting the weights, the densities of related solutions were calculated and tabulated with reference to the standard density of water at $30^{\circ} \mathrm{C}$ (room temperature) i.e. $0.99571 \mathrm{~g} / \mathrm{cm}^{3}$.

Surface tension measurements were carried out on a stalagmometer. The surface tension of SDS in absence and presence of salts was measured by drop count method using a stalagmometer. It was designed by Troube and consists of a pipette with a capillary outflow to be the end of which is flattened out. This is done to give a larger dropping surface. The surface is carefully ground flat and polished. Before using the stalagmometer was first carefully washed with a solution of chromic acid and then with 


\section{K. Limbu et al. / BIBECHANA 11(1) (2014) 79-85: (Online Publication: March, 2014) p.81}

distilled water. Finally it was washed with acetone and dried. The stalagmometer was held vertical and was not shaken because otherwise the drop will fall out even before attaining its maximum size. In this process, first the stalagmometer was filled with distilled water as above without changing the pressure. Then the drop count was started. By following the same process all the liquids or solutions of varied strength of SDS in presence and absence of $\mathrm{Na}_{2} \mathrm{SO}_{4}$ and $\mathrm{ZnSO}_{4}$ was measured.

\section{Results and Discussion}

The surface tension of SDS in distilled water and in aqueous solution of $\mathrm{Na}_{2} \mathrm{SO}_{4}$ and $\mathrm{ZnSO}_{4}$ were calculated from equation (1) and were tabulated in Table 1A, 1B and 1C. The graphical representations of the surface tension of SDS in distilled water and in aqueous solution of $\mathrm{Na}_{2} \mathrm{SO}_{4}$ and $\mathrm{ZnSO}_{4}$ with $\log$ [SDS] are shown in Figs. 1-3. Since, there was sharp decrease of surface tension on increase of surfactant concentrations. According to the experimental calculations and determinations, the surface tension was found to be decreased in presence of salts .i.e. $\mathrm{Na}_{2} \mathrm{SO}_{4}$ and $\mathrm{ZnSO}_{4}$.

The surface tension value was high in case of water because of absence of externally added salts. Since, on the addition of inorganic salts, affect surfactant aggregation mainly through reducing the electrostatic interaction among the surfactant head groups and consequently decrease the surface tension of the surfactant molecules.

In the case of $\mathrm{Na}_{2} \mathrm{SO}_{4}$ and $\mathrm{ZnSO}_{4}$, the sodium ion $\left(\mathrm{Na}^{+}\right)$is larger than the $\mathrm{Zinc}$ ion $\left(\mathrm{Zn}^{2+}\right)$ because, the Zinc cation, $\mathrm{Zn}^{2+}$, has a greater cationic charge than the $\mathrm{Na}^{+}$cation. The surface tension of SDS in presence of $\mathrm{Na}_{2} \mathrm{SO}_{4}$ is more than in presence of $\mathrm{ZnSO}_{4}$ because the smaller ions are strongly hydrated, so they need to pull more water molecules with them which make them less mobile. Thus, due to zinc ions $\left(\mathrm{Zn}^{2+}\right)$.i.e. counter ions reduced largely the electrostatic interaction among the surfactant molecules and decreased surface tension largely.

When surface tension of a solution is plotted against $\log [\mathrm{C}]$, where $\mathrm{C}$ is the concentration of surfactant then it gives a curve. The two fitted lines meet in the curve at the particular point. That point of intersection is known as cmc of the solution.

Table 1A: Surface tensions of SDS in distilled water.

\begin{tabular}{|c|c|c|}
\hline Solvent & Concentration $\left(\mathrm{mol} / \mathrm{I}^{-1}\right)$ & Surface tension $(\mathrm{dyne} / \mathrm{cm})$ \\
\hline & 0.02402 & 31.80359 \\
0.01801 & 32.11061 \\
0.01351 & 32.42408 \\
0.01013 & 32.74436 \\
0.00760 & 33.40919 \\
& 0.00570 & 35.97611 \\
& 0.00428 & 37.62764 \\
& 0.00321 & 38.96942 \\
& 0.00241 & 39.91825 \\
& 0.00180 & 40.40978 \\
& 0.00135 & 40.91390 \\
& 0.00102 & 41.43103 \\
\hline
\end{tabular}


K. Limbu et al. / BIBECHANA 11(1) (2014) 79-85: (Online Publication: March, 2014) p.82

Table 1B: Surface tensions of SDS in the presence of $\mathrm{Na}_{2} \mathrm{SO}_{4}$.

\begin{tabular}{|c|c|c|}
\hline Solvent & Concentration $\left(\mathrm{mol} / \mathrm{I}^{-1}\right)$ & Surface tension $(\mathrm{dyne} / \mathrm{cm})$ \\
\hline & 0.02400 & 29.83293 \\
0.02000 & 30.10266 \\
0.01667 & 30.66151 \\
0.01389 & 31.54318 \\
& 0.01157 & 32.15982 \\
& 0.00965 & 33.13277 \\
& 0.00804 & 33.81490 \\
$\mathrm{Na}_{2} \mathrm{SO}_{4}$ & 0.00670 & 34.16566 \\
& 0.00558 & 40.99797 \\
& 0.00465 & 43.73001 \\
& 0.00388 & 44.92753 \\
& 0.00323 & 47.53145 \\
& 0.00269 & 50.45586 \\
& 0.00224 & 53.76411 \\
& 0.00187 & 56.54468 \\
& 0.00156 & 58.56345 \\
& 0.00130 & 59.62791 \\
& & \\
& &
\end{tabular}

Our calculation of cmc of SDS in distilled water at room temperature found to be $8.29 \mathrm{mM}$ which is almost matching with $9.00 \mathrm{mM}$ by surface tension method [5]. When surfactant and salt are mixed in solution, salting-out phenomenon often happens [6-9].

According to hydration theory [10] salting-out is the result of preferential movement of water molecules, which immobilize and quench their role as solvents, from coordination shells of surfactant molecules to those of salts. The effects of halide salts on the growth of micelles in ionic surfactant solutions have been systematically studied $[11,12]$.

With the addition of inorganic salts, the reduced electrostatic repulsion among the surfactant head groups is a key factor to influence the morphology of aggregates in ionic surfactant solutions. For conventional single-chain cationic surfactants, micelles may change from global to rod like or wormlike with the addition of inorganic salts $[13,14]$.

Salts decrease the cmc in the order: $\mathrm{ZnSO}_{4}<\mathrm{Na}_{2} \mathrm{SO}_{4}$. Here $\mathrm{Zn}^{++}$is least effective in decreasing the cmc due to small size and large hydrated radius and would act as a water-structure promoter decreasing the availability of water to the micelles. Therefore, upon addition of $\mathrm{ZnSO}_{4}$ and $\mathrm{Na}_{2} \mathrm{SO}_{4}$ in $\mathrm{SDS}, \mathrm{Na}_{2} \mathrm{SO}_{4}$ is more effective in reducing the cmc of SDS. Hence in our case $\mathrm{Na}_{2} \mathrm{SO}_{4}$ decreases the cmc of SDS more than $\mathrm{ZnSO}_{4}$ (Table 2). 
K. Limbu et al. / BIBECHANA 11(1) (2014) 79-85: (Online Publication: March, 2014) p.83

Table 1C: Surface tensions of SDS in the presence of $\mathrm{ZnSO}_{4}$.

\begin{tabular}{|c|c|c|}
\hline Solvent & Concentration $\left(\mathrm{mol} / \mathrm{l}^{-1}\right)$ & Surface tension $(\mathrm{dyne} / \mathrm{cm})$ \\
\hline & 0.06017 & 27.16200 \\
0.05014 & 27.37816 \\
0.04179 & 27.59907 \\
0.03482 & 28.06390 \\
& 0.02902 & 28.29980 \\
& 0.02418 & 28.79153 \\
& 0.02015 & 29.56571 \\
$\mathrm{ZnSO}_{4}$ & 0.01679 & 30.10506 \\
& 0.01399 & 30.66502 \\
& 0.01166 & 30.95195 \\
& 0.00972 & 31.24480 \\
& 0.00810 & 31.54408 \\
& 0.00675 & 31.84879 \\
& 0.00562 & 34.89688 \\
& 0.00469 & 37.27535 \\
& 0.00391 & 40.00185 \\
& 0.00325 & 41.00095 \\
& 0.00271 & 41.51947 \\
& 0.00226 & 41.51852 \\
& 0.00188 & 41.51804 \\
\hline
\end{tabular}

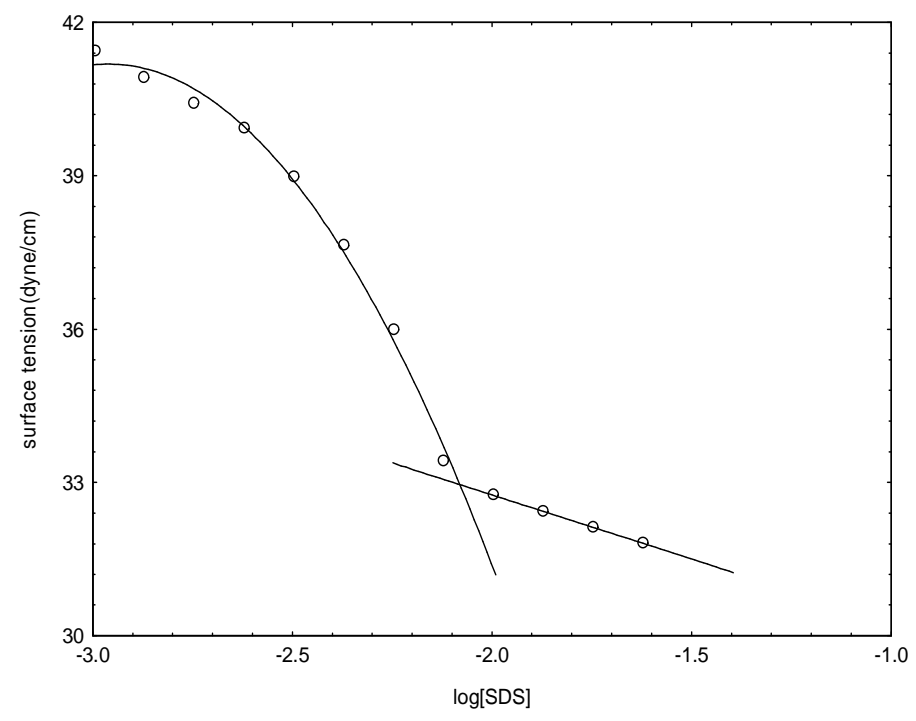

Figure 1: Variation of surface tension of SDS with $\log$ [SDS] in distilled water at room temperature. 
K. Limbu et al. / BIBECHANA 11(1) (2014) 79-85: (Online Publication: March, 2014) p.84

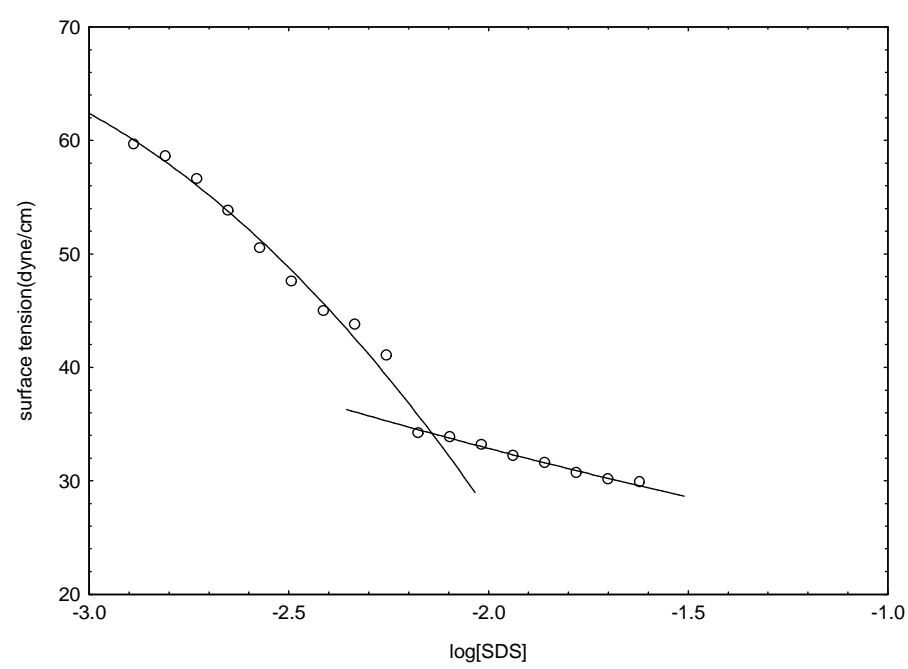

Figure 2: Variation of surface tension of SDS with log [SDS] in aqueous solution of $\mathrm{Na}_{2} \mathrm{SO}_{4}$ at room temperature.

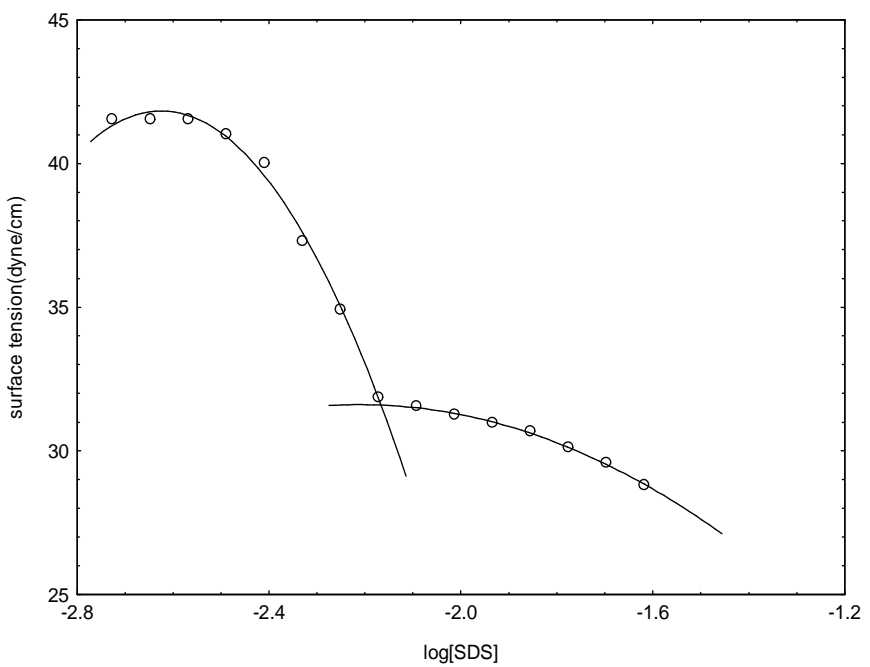

Figure 3: Variation of surface tension of SDS with $\log$ [SDS] in aqueous solution of $\mathrm{ZnSO}_{4}$ at room temperature.

Table 2: Critical micelle concentrations of SDS obtained from surface tension measurement in distilled water, aqueous solution of $\mathrm{Na}_{2} \mathrm{SO}_{4}$ and $\mathrm{ZnSO}_{4}$.

\begin{tabular}{|c|c|c|c|}
\hline Solvent & $\begin{array}{c}\text { Distilled water } \\
C m c(\mathrm{mM})\end{array}$ & $\begin{array}{c}0.01 \mathrm{M} \mathrm{ZnSO}_{4} \\
C m c(\mathrm{mM})\end{array}$ & $\begin{array}{c}0.01 \mathrm{M} \mathrm{Na}_{2} \mathrm{SO}_{4} \\
C m c(\mathrm{mM})\end{array}$ \\
\hline Surface tension & 8.29 & 7.01 & 6.02 \\
\hline
\end{tabular}




\section{Conclusion}

The following conclusions have been drawn from above results and discussion. The results showed the decrease in surface tension of sodium dodecyl sulphate (SDS) at room temperature in presence of $\mathrm{Na}_{2} \mathrm{SO}_{4}$ and $\mathrm{ZnSO}_{4}$. The surface tension of sodium dodecyl sulphate is found less in presence of $\mathrm{ZnSO}_{4}$ than $\mathrm{Na}_{2} \mathrm{SO}_{4}$ in aqueous media and the cmc of sodium dodecyl sulphate decreases more in $\mathrm{Na}_{2} \mathrm{SO}_{4}$ comparison with presence of $\mathrm{ZnSO}_{4}$.

\section{Acknowledgments}

One of the authors (Kuber Limbu) is thankful to the University Grants Commission (UGC), Nepal, for providing grants for M. Sc. dissertation work and the authors are grateful to Associate Professor G.S. Shrivastav, Head of the Department of Chemistry, Mahendra Morang Adarsh Multiple Campus, Tribhuvan University, Biratnagar, Nepal for providing the research facilities to conduct this research work.

\section{References}

[1] M. Austin, B.B. Bright, E .A. Simpson, J. Colloid and Interface Sci., 23 (1967) 108 .

[2] J .A. Caskey, W .B. Barlage, J. Colloid and Interface Sci., 35 (1971) 46.

[3] J. Piret, A. Désormeaux, M. G. Bergeron, Curr. Drug Targets, 3 (2002) 17.

[4] J. Piret, J. Lamontagne, J. Bestman-Smith, S. Roy, P. Gourde, A. Désormeaux, R.F. Omar, J. Juhász, M. G. Bergeron, J. Clin. Microbiol., 38 (2000) 110.

[5] M. A. Bahri, M. Hoebeke, A. Grammenos, L. Delanaye, N. Vandewalle, A. Seret, Colloids and Surfaces A: Physicochem. Eng. Aspects, 290 (2006) 206.

[6] P. Mukerjee, C. C. Chan, Langmuir, 18 (2002) 5375.

[7] Y. Defeng, X. Huang, M. Deng, Y. Lin, L. Jiang, J. Huang, Yi. Wang, J. Phys. Chem. B, 114 (2010) 14955.

[8] F. A. Long, W. F. McDevit, Chem. Rev., 51 (1952) 119.

[9] L.Wattebled, A. Laschewsky, Langmuir, 23 (2007) 10044.

[10] P. K. Grover, R. L. Ryall, Chem. Rev., 105 (2005) 1.

[11] M. L. Corrin, W. D. Harkins, J. Am. Chem. Soc., 69 (1947) 683.

[12] V. K. Aswal, P. S. Goyal, Chem. Phys Lett., 364 (2002) 44.

[13] J.H. Mu, G.Z. Li, X. L. Jia, H.X. Wang, G.Y. Zhang, J. Phys. Chem. B, 106 (2002) 11685.

[14] A. Khatory, F. Lequeux., F. Kern, S. J. Candau, Langmuir, 9 (1993) 1456. 